\title{
Teaching
Methods
}

\section{Strengthening Teaching Effectiveness Through Cooperative Learning Activities}

\author{
Elsa Sánchez ${ }^{1,3,4}$ and Richard Craig ${ }^{1,2}$
}

ADDITIONAL INDEX WORDS. teaching methods, group work, education

SUMMARY. A variety of cooperative activities are part of the plant systematics course at The Pennsylvania State University: a learning fair hosted by the students enrolled in the course for elementary school students, applied laboratory examinations, and applied laboratory exercises. Each activity was constructed to engage students in the learning process as well as to aid in developing useful skills for future employment. A survey administered to students enrolled in the course from 2003 to 2005 revealed that most students "strongly agreed" or "agreed" that they liked working in cooperative groups and learned from other group members. Student participation in the lecture portion of the course increased as cooperative activities were completed. Organization and planning were vital to using these activities, as were small groups and adequate incentives for completing activities.

$\mathrm{C}$ ooperative learning activities are designed by the course instructor for students to complete in groups using information and materials provided by the instructor (Ventimiglia, 1994). Using a variety of cooperative activities in teaching addresses differences in student learning styles (McCormick and Whittington, 2000; Murano and Knight,

Use of trade names does not imply endorsement of the products named or criticism of similar ones not named.

The authors express sincere appreciation to Lisa Gamble, Laura Krebs, and the State College Friends School for their participation in the Asteraceae Fair. We also express sincere appreciation to Kenneth Myers for his support of this class in the roles of greenhouse technician and teaching assistant and to the numerous undergraduate and graduate teaching assistants for their efforts.

${ }^{1}$ Department of Horticulture, The Pennsylvania State University, University Park, PA 16802.

${ }^{2}$ Assistant Professor of Horticultural Systems Management.

${ }^{3}$ J. Franklin Styer Professor Emeritus of Horticultural Botany.

${ }^{4}$ Corresponding author. E-mail: esanchez@psu.edu. 1999a), thereby facilitating student learning. While traditional lectures transfer knowledge, they are less conducive in facilitating higher levels of thinking, such as the application of concepts and analysis and synthesis of information (Bull and Clausen, 2000; Murano and Knight, 1999b). Academic challenges should be constructed to engage students in developing skills in higher-level thinking [application, analysis, synthesis, and evaluation (McCormick and Whittington, 2000)]. Cooperative learning activities engage students (Murano and Knight, 1999b; Ventimiglia, 1994) by being interesting and giving them responsibility in the teaching and learning process (Caprio, 1993). In addition to higher-level thinking, students develop skills not promoted in traditional lecture formats: productive peer-to-peer interactions (Bull and Clausen, 2000), creativity, effective communication, and time management (Murano and
Knight, 1999b). Cooperative learning activities also can encourage student independence and self-directedness (Pennington, 2004). The plant systematics course offered through the Department of Horticulture at The Pennsylvania State University includes several cooperative learning activities to engage students in course topics.

Plant systematics is a second-year/ sophomore level, 3-credit, required course for undergraduate students majoring in horticulture and is offered each spring semester. The course includes two weekly lecture sessions (50 min each) and one weekly laboratory session (115 min). The overall objective of the course is for students to explore the biosystematics and taxonomy of plants with a focus on agrophytic families. In 1995, the course was reformatted based on a three-dimensional model: plant identification, systematics, and enhancement/ethnobotany. The plant identification dimension includes nomenclature, culture, and use of horticultural plants emphasizing 14 families. The systematics dimension includes classical, numerical, biochemical, and molecular protocols of systematics. Finally, the horticultural enhancement dimension includes historical uses of plants, relationships between plants and people, evolutionary aspects, and geographic paradigms.

Among the teaching materials and activities developed for the revamped course is a website containing PowerPoint (Microsoft, Redmond, Wash.) presentations that students can use to preview or review lecture topics. Each student delivers a 10-min presentation on the taxonomic characteristics and ethnobotanical information of a plant family and completes three in-class examinations of lecture topics. Cooperative learning activities developed are a learning fair for elementary school students and applied laboratory exercises and examinations.

The need for adequate incentives for student participation in cooperative learning activities has been documented (Henneberry and Beshear, 1995; Murano and Knight, 1999b). While not the only incentive, each activity accounted for a percentage of the overall course grade: $6 \%$ for the learning fair, $14 \%$ for the applied laboratory exercises, and $11 \%$ for the applied laboratory examinations. 
Asteraceae Fair. The Asteraceae Fair is a learning fair for elementary school students (third and fourth grade) hosted by the students in the plant systematics course. The fair is a teaching tool as well as a means to use concepts the students have learned and relate them to the interest/ability level of 8- to 10-year-olds. Teamteaching course topics to others can be an effective method for increasing technical knowledge (Barkley, 2003). Students in the plant systematics course are assigned to groups of three or four students to create an activity (Fig. 1) and to develop a handout to teach the elementary students about the plant family Asteraceae. Instructions on developing the fair activities and handout are in Fig. 2.

Groups prepare for the Asteraceae Fair outside of class. Students have deadlines for submitting descriptions of their fair activity and handout so that the instructor is informed and can guide groups when duplicate or ineffective activities or handouts are proposed. To complete this activity, students must be creative to generate and develop ideas for their fair activity. They develop effective time management skills by sharing the workload to meet deadlines. Additionally, the students develop communication skills to relate concepts to their peers. Students must also have a thorough understanding of topics presented and be able to

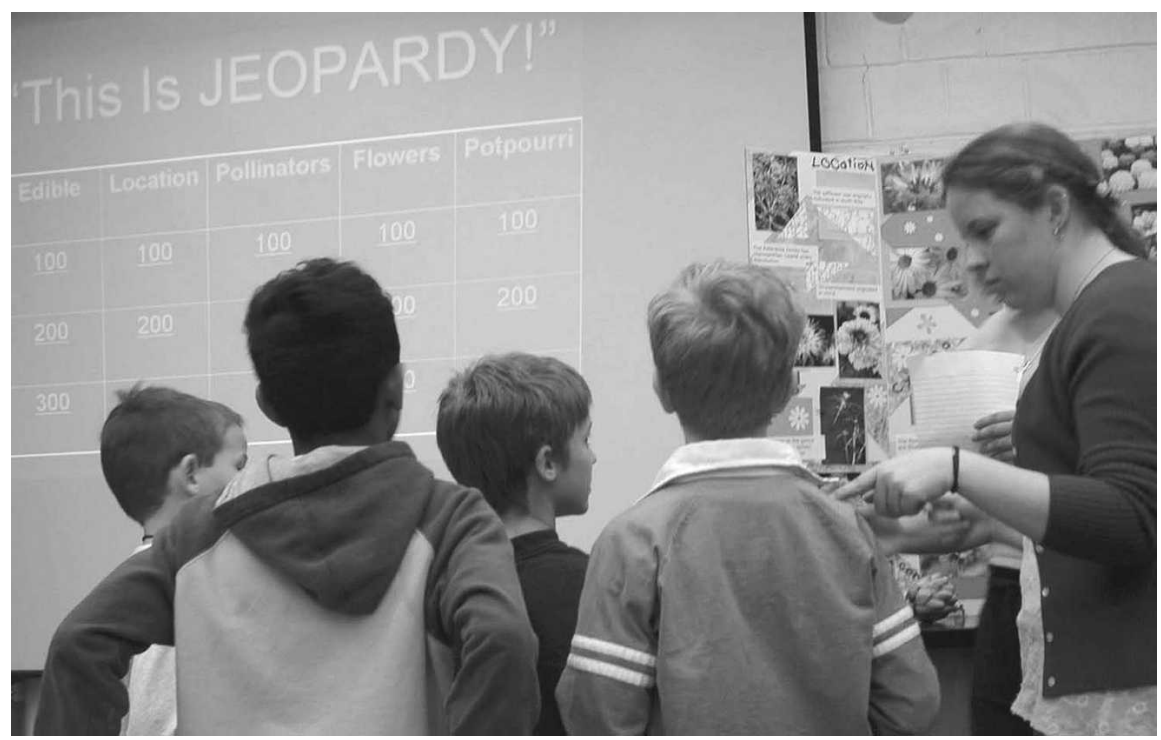

Fig. 1. Elementary students participating in an activity designed and administered by a cooperative group of undergraduate students in the plant systematics course as a part of a learning fair.

effectively communicate them to the 8 - to 10-year-old elementary school students. Thorough understanding and effective communication are important outcomes of problembased learning (Duch, 1996).

LABORATORY SESSIONS. Students complete 15 laboratory sessions. The first two sessions focus on identification and the proper terminology for vegetative and reproductive morphological characteristics. The remaining sessions each focus on an important agrophytic family. Each session begins with an oral presentation to describe characteristics and ethnobotanical information pertinent to the family. Students also have the option of downloading and printing a handout from the course web site that summarizes the oral presentation. Students are then assigned to groups of two or three students (different groups for each laboratory session) to complete five or six applied laboratory exercises. Each exercise consists of a question(s) pertaining to seeds, young plants, mature plants, flowers, or plant uses. Exercise questions are designed to reinforce concepts delivered in the presentation. As an example, students may be asked to draw floral diagrams or write floral formulas for flower specimens.

In this cooperative learning activity students practice generating and sharing ideas, creative thinking, applying course concepts to "real

Hortechnology · April-June 2007 17(2) world" situations (Clary, 1997) and receiving and responding to peer feedback. While completing the exercises, it is common to observe students teaching and learning from their peers.

"Putting It Together". After completing three or four laboratory sessions, an applied laboratory examination entitled "Putting It Together" is administered to the students. Each examination consists of five to six stations; each containing a question(s) related to live plant specimens, photographs, models, or food items (Fig. 3). On the day of each examination, students are randomly assigned to groups of two or three students. Students do not know who will be in their groups before arriving to class. This is to encourage studying of all the topics covered on the examination rather than dividing topics between members of each group. In these groups, students develop skills in higher-level thinking through problem solving. Students are allowed several minutes to complete each station and must use effective time management. Verbal communication of ideas is practiced, as well as, in some cases, conflict resolution. Students must have a clear understanding of course topics and be able to communicate their answers effectively, particularly when answers conflict with other group members.

STUDENT SURVEY. A survey was administered to students enrolled in the plant systematics course from 2003 to 2005 to determine their assessment of the cooperative learning activities used in the course. The Office of Research Protection at The Pennsylvania State University approved the survey. Forty-seven students completed the survey $(81 \%$ response rate). Responses were analyzed with Wilcoxon's signed rank test using SAS (version 9.1.3; SAS Institute, Cary, N.C.).

Most students liked working in cooperative groups for the learning fair [35 "strongly agree" or "agree" responses (Table 1)]. Comments from students included "it was a fun way of applying the knowledge," "I really enjoyed this project," and "you not only had to know your information but also learn how to teach it on another level, so that the kids would too be able to understand." Most students also liked 


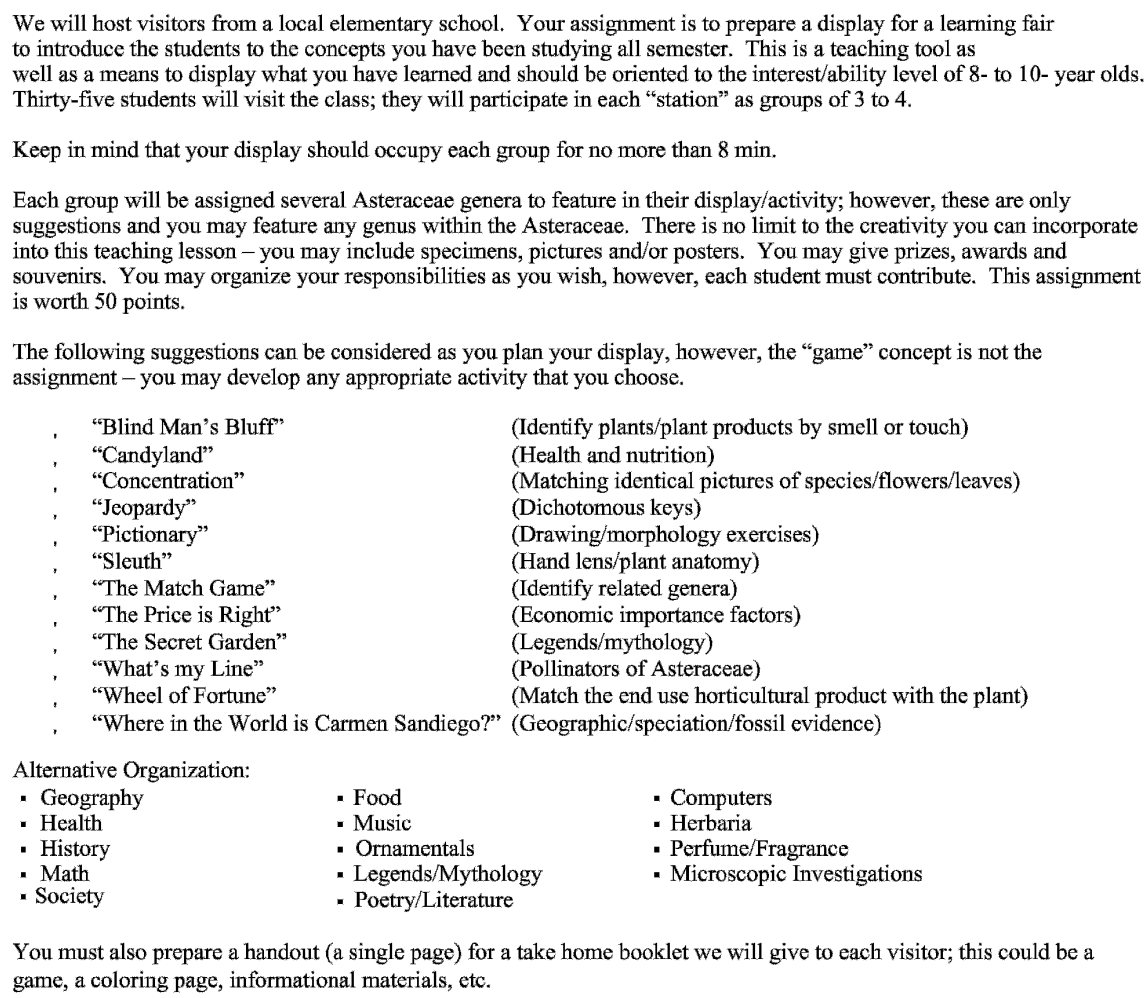

Each group will be assigned several Asteraceae genera to feature in their display/activity; however, these are only suggestions and you may feature any genus within the Asteraceae. There is no limit to the creativity you can incorporate into this teaching lesson - you may include specimens, pictures and/or posters. You may give prizes, awards and souvenirs. You may organize your responsibilities as you wish, however, each student must contribute. This assignment is worth 50 points.

The following suggestions can be considered as you plan your display, however, the "game" concept is not the assignment - you may develop any appropriate activity that you choose.

\begin{tabular}{|c|c|}
\hline "Blind Man's Bluff" & (Identify plants/plant products by smell or touch) \\
\hline "Candyland" & (Health and nutrition) \\
\hline "Concentration" & (Matching identical pictures of species/flowers/leaves) \\
\hline "Jeopardy" & (Dichotomous keys) \\
\hline "Pictionary" & (Drawing/morphology exercises) \\
\hline "Sleuth" & (Hand lens/plant anatomy) \\
\hline "The Match Game" & (Identify related genera) \\
\hline "The Price is Right" & (Economic importance factors) \\
\hline "The Secret Garden" & (Legends/mythology) \\
\hline "What's my Line" & (Pollinators of Asteraceae) \\
\hline "Wheel of Fortune" & (Match the end use horticultural product with the plant) \\
\hline
\end{tabular}

Alternative Organization:

- Geography - Food - Computers

- Health - Music Herbaria

- History - Ornamentals . Perfume/Fragrance

- Math - Legends/Mythology - Microscopic Investigations

- Society - Poetry/Literature

You must also prepare a handout (a single page) for a take home booklet we will give to each visitor; this could be a game, a coloring page, informational materials, etc.

Fig. 2. Instructions provided to students in the plant systematics course for developing an activity in cooperative groups for a learning fair.

I. This plant shares the following characteristics with a family discussed in previous laboratory sessions. Name the family:

$$
\begin{aligned}
& \text { Four petals } \\
& \text { Hirsute pubescence } \\
& \text { Many stamens } \\
& \text { Lobed leaves } \\
& \text { Fruit is a capsule }
\end{aligned}
$$$$
\text { Family }
$$

II. 1. This fruit is a (grain/pepo/drupe/silique/berry/capsule/legume/achene/caryopsis/other).

2. In this flower, is the ovary superior or inferior?

3. What family is are these specimens in?

\begin{tabular}{|c|c|c|c|}
\hline A. Liliaceae & Brassicaceae & Rosaceae & Poaceae \\
\hline B. Rosaceae & Fabaceae & Liliaceae & Cucurbitaceae \\
\hline C. Liliaceae & Brassicaceae & Orchidaceae & Fabaceae \\
\hline
\end{tabular}

4. What order is this family in?

III. Which fruit is a(n): (write the correct letter)

$$
\begin{aligned}
& \text { Legume } \\
& \text { Capsule } \\
& \text { Pome } \\
& \text { Achene }
\end{aligned}
$$

IV. What family represented by the sample? (circle correct answer).

V. The inflorescence is a(n): (circle correct answer).

$\begin{array}{lll}\text { A. Raceme } & \text { Umbel } & \text { Spike } \\ \text { B. Spadix/Spathe } & \text { Simple/Single } & \text { Panicle } \\ \text { C. Corymb } & \text { Head } & \text { Panicle }\end{array}$

VI. This flower/diagram illustrates: (circle correct answer).
1. Apocarpy
Syncarpy
2. Single ovules
Multiple ovules
3. The family is: Rosaceae
Fabaceae
Orchidaceae Solanaceae
Other

Fig. 3. Sample questions used in the applied laboratory examinations that students enrolled in the plant systematics course complete in cooperative groups. working in cooperative groups for the laboratory examinations [39 "strongly agree" or "agree" responses (Table 1)]. Comments from the students included "that's the way it would be, out in the job site," "for the most part, they really reinforced what we learned in lecture and in the lab," "I think that this was an excellent "closure' on the topics," and "it showed just how much we learned and what we needed to work on." Students preferred working in groups for laboratory examinations more than for the learning fair $(P=0.0366)$. Students may have favored working in cooperative groups during class, as was the case for the laboratory examinations, vs. outside of class, as was the case for the preparing for the learning fair.

Most students learned from other group members while completing laboratory exercises and examinations [38 and 36 "strongly agree" or "agree" responses, respectively (Table 2)]. Student responses indicated that learning from group members during laboratory exercises and laboratory examinations was comparable $(P=0.2103)$. Student proficiency with course topics was at a beginning level when deliberating during laboratory exercises while successful completion of laboratory examinations required more advanced mastery of course topics. In both situations student comprehension of course topics was increased through interactions with group members.

BEYOND THE SURVEY-LESSONS LEARNED AS THE COURSE INSTRUCTOR. In general, students responded favorably to working in cooperative groups and benefited from the knowledge of other group members. Another benefit was that student participation or involvement during class lectures increased as cooperative learning activities were completed. Students were assigned to groups rather than being allowed to self-select groups for each activity. This was done to facilitate the students in meeting their peers; by the end of the semester, each student knew every student in the class. It allowed the students to network with each other, which can have positive implications for their future careers in the horticultural industry. Perhaps camaraderie with peers created an 
Table 1. Responses of students $(n=47)$ enrolled in the plant systematics from 2003 to 2005 to the survey statements "I liked working in groups for preparing and presenting the Asteraceae Fair activity" and "I liked working in groups for the laboratory examinations."

\begin{tabular}{lcc}
\hline Response & $\begin{array}{c}\text { Asteraceae Fair } \\
\text { (no. of responses) }\end{array}$ & $\begin{array}{c}\text { Laboratory examinations } \\
\text { (no. of responses) }\end{array}$ \\
\hline Strongly agree & 9 & 19 \\
Agree & 26 & 20 \\
Neither agree nor disagree & 8 & 5 \\
Disagree & 3 & 3 \\
Strongly disagree & 1 & 0 \\
\hline
\end{tabular}

Table 2. Responses of students $(n=47)$ enrolled in the plant systematics from 2003 to 2005 to the survey statements "I learned from other members in my group about concepts that I was unclear on" during laboratory sessions and applied laboratory examinations.

\begin{tabular}{lcc}
\hline Response & $\begin{array}{c}\text { Laboratory sessions } \\
\text { (no. of responses) }\end{array}$ & $\begin{array}{c}\text { Laboratory examinations } \\
\text { (no. of responses) }\end{array}$ \\
\hline Strongly agree & 15 & 15 \\
Agree & 23 & 21 \\
Neither agree nor disagree & 7 & 6 \\
Disagree & 1 & 3 \\
Strongly disagree & 1 & 2 \\
\hline
\end{tabular}

atmosphere more conducive to taking risks in the form of asking questions or contributing ideas during lectures. Cooperative learning activities can promote student self-esteem and taking risks outside of one's comfort zone (Caprio, 1993).

Organization and planning were vital to the success of these cooperative learning activities. As also observed by Bull and Clausen (2000) and Ventimiglia (1994), more time was required to prepare these $\mathrm{co}^{-}$ operative activities compared with traditional lecturing which is used by the course instructor in other courses. Additionally, during the implementation of the activities the role of the instructor was that of a facilitator or coach rather than a teacher. The additional efforts in organization and planning were offset by perceived benefits to the students: increased sharing of knowledge, more open communication and peer-topeer interaction (Bull and Clausen, 2000), and development of skills that can be used in future careers (Clary, 1997).
Small cooperative groups of two to four members and adequate incentive for completing activities were also thought necessary in the execution of this teaching method. As noted previously (Bull and Clausen, 2000), using small groups created a situation where students could be more comfortable communicating with their peers. Also, using small groups encouraged all members to participate in the activities and decreased the ability of students to be "free riders" (Henneberry and Beshear, 1995). Additionally, as an incentive, each activity was assigned a value of the total class grade; this value was made known to students on the first day of class.

In general, the students benefited from working in cooperative groups, as was documented in the survey as well as in other studies of cooperative learning methods (Bull and Clausen, 2000; Duch, 1996; Henneberry and Beshear, 1995; Murano and Knight, 1999b). As stated by Henneberry and Beshear (1995) "Many challenges facing agriculture today are more appropriately solved by groups rather than individuals; thus group exercises are valuable to help develop the students' teamwork and interpersonal skills."

\section{Literature cited}

Barkley, A.P. 2003. Learning the economics of international trade by teaching it to others: a class project on globalization. North Amer. Colleges Teachers Agr. J. 47:25-31.

Bull, N.H. and J.C. Clausen. 2000. Structured group learning in undergraduate and graduate courses. J. Natural Resources Life Sci. Educ. 29:46-50.

Caprio, M.W. 1993. Cooperative learningthe jewel among motivational-teaching techniques. J. College Sci. Teachers. 22: 279-281.

Clary, C.R. 1997. Using peer review to build project teams: A case study. North Amer. Colleges Teachers Agr. J. 41:25-27.

Duch, B.J. 1996. Problem-based learning in physics: the power of students teaching students. J. College Sci. Teachers. 25:326-329.

Henneberry, S.R. and M. Beshear. 1995. Bridging the gap between theory and reality: a comparison of various teaching methods. North Amer. Colleges Teachers Agr. J. 39:15-17.

McCormick, D.F. and M.S. Whittington. 2000. Assessing academic challenges for their contribution to cognitive development. J. Agr. Educ. 41:114-122.

Murano, P.S. and T.D. Knight. 1999a. Determination of learning styles in an introductory food science course. North Amer. Colleges Teachers Agr. J. 43:50-53.

Murano, P.S. and T.D. Knight. 1999b. Introducing a cooperative learning term project into an introductory food science course. North Amer. Colleges Teachers Agr. J. 41:21-25.

Pennington, P. 2004. Professional development in agriculture: opening doors through creative leadership. North Amer. Colleges Teachers Agr. J. 48:27-30.

Ventimiglia, L.M. 1994. Cooperative learning at the college level. Thought Action 9:5-30. 